\title{
ATAKI: JOGO DE TABULEIRO PARA O APOIO AO PROCESSO DE ENSINO APRENDIZAGEM NA DISCIPLINA DE OPERAÇÕES DE SEPARAÇÃO
}

Kátia Simone Teixeira da Silva de La Salles - katia.salles@ufma.br*

Departamento de Tecnologia Química - DETQI

Wendell Ferreira de La Salles - wendell.salles@ufma.br*

Departamento de Tecnologia Química - DETQI

Janyne Palheta Ramos - janyne.ramos@ discente.ufma.br*

Charbel Nagib Mouchrek - charbel.nm@ discente.ufma.br*

Helcai Rhony Lopes Santos - helcai.rhony@ discente.ufma.br*

Jhonny Taveira do Espírito Santo - jhonny.taveira@discente.ufma.br*

*Universidade Federal do Maranhão

Av. dos Portugueses, 1966, Bacanga

CEP 65080-805 - São Luís - Maranhão

Resumo: O uso de jogos na educação vem aumentando ao longo do tempo. A utilização dessa estratégia prima principalmente por aumentar a motivação dos estudantes, além de possibilitar a discussão do conhecimento favorecendo a aprendizagem e sua avaliação. Este artigo descreve uma atividade construtivista para apoiar o processo de ensino aprendizagem na disciplina de operações de separação, componente curricular obrigatório dos cursos de Engenharia Química, Engenharia de Alimentos e de Química Industrial (no âmbito da Universidade Federal do Maranhão - UFMA), que consiste no desenvolvimento de um jogo de tabuleiro, em equipe, com ênfase nos conteúdos de ciclone e hidrociclone. O trabalho descreve o detalhamento da dinâmica, assim como o relato de aplicação e uma avaliação pós-jogo.

Palavras-chave: Jogo de Tabuleiro. Operações de Separação. Ciclone. Hidrociclone.

\section{INTRODUÇÃ̃}

Nos últimos anos, no Brasil, a educação tem passado por mudanças, a exemplo das novas Diretrizes Curriculares Nacionais (DCNs) para os cursos de graduação em Engenharia, publicadas em abril de 2019, que proporcionaram muitas reflexões a respeito de metodologias 
e de recursos a serem utilizados nas salas de aula. As DCNs de Engenharia trazem conceitos atuais como a formação baseada por competências, o foco na prática, a aprendizagem ativa e uma maior flexibilidade na constituição do currículo. Além disso, ao defender a adoção de metodologias ativas de aprendizagem, as novas diretrizes colocam os estudantes como agentes ativos no processo de ensino e aprendizagem e viabiliza a formação por competências (OLIVEIRA, 2019).

Segundo Elmôr et al (2019), um ambiente de aprendizagem ativa deve promover situações que levem os estudantes a produzirem significados para os conceitos em construção.

Para Piaget (1975):

[...] os métodos chamados ativos são os únicos capazes de desenvolver a personalidade intelectual e que pressupõem necessariamente a intervenção de um coletivo, ao mesmo tempo formador da personalidade moral e fonte de trocas intelectuais organizadas pelo professor, visando à participação do estudante.

Nesse sentido, a Aprendizagem Baseada em Jogos (GBL de Game Based Learning), aplicada ao ensino superior, toma fôlego como uma das estratégias possíveis para a construção do conhecimento, com foco na aprendizagem ativa.

O GBL é uma metodologia pedagógica que foca na concepção, desenvolvimento, uso e aplicação de jogos na educação e na formação (CARVALHO, 2015). Segundo Felczak (2017), a metodologia GBL proporciona a participação ativa, por meio da manipulação de recursos e a compreensão de conceitos empregados no desenvolvimento do jogo.

É sabido que os jogos estimulam a criatividade, a comunicação, as relações interpessoais e a espontaneidade, levando à efetiva apropriação do conhecimento. Isto propicia o desenvolvimento cognitivo do aluno de maneira lúdica e prazerosa. Para desenvolver um jogo, o aluno deve ser capaz de planejar, desenvolver e aplicar, favorecendo sua aprendizagem, uma vez que será necessário estudar para conhecer o conteúdo e para produzir o material didático (conteúdo, regras e estratégias) (RIBEIRO, 2018).

Este trabalho propôs uma atividade construtivista utilizando como premissa a criação de um jogo de tabuleiro, por parte dos estudantes, para apoiar o processo de ensino aprendizagem na disciplina de operações de separação, com posterior aplicação.

O jogo de tabuleiro, como recurso didático, possibilitou um ambiente sistemático e interativo para construção de conhecimento, pois permitiu aos estudantes modos diferenciados de aprendizagem, ajudando e facilitando a fixação de conteúdos recém-trabalhados em sala, além de trabalhar a criatividade e de estimular a interação entre os estudantes (em grupos, durante a confecção do jogo, ou entre os competidores no ato do jogo).

\section{METODOLOGIA}

O jogo de tabuleiro "Ataki" foi proposto no âmbito do componente curricular (CC) de Operações de Separação I, como uma atividade construtivista, e desenvolvido por estudantes 
do Curso de Química Industrial da Universidade Federal do Maranhão, que estavam matriculados no CC do segundo semestre do ano de 2019.

O jogo "Ataki" foi planejado com referência nos assuntos de ciclones e hidrocilones, e poderá ser usado para avaliação da aprendizagem destes conteúdos nos cursos de Engenharia Química, Engenharia de Alimentos e Química Industrial, no âmbito do estudo das operações de separação.

A Figura 1 apresenta a estrutura do jogo criado.

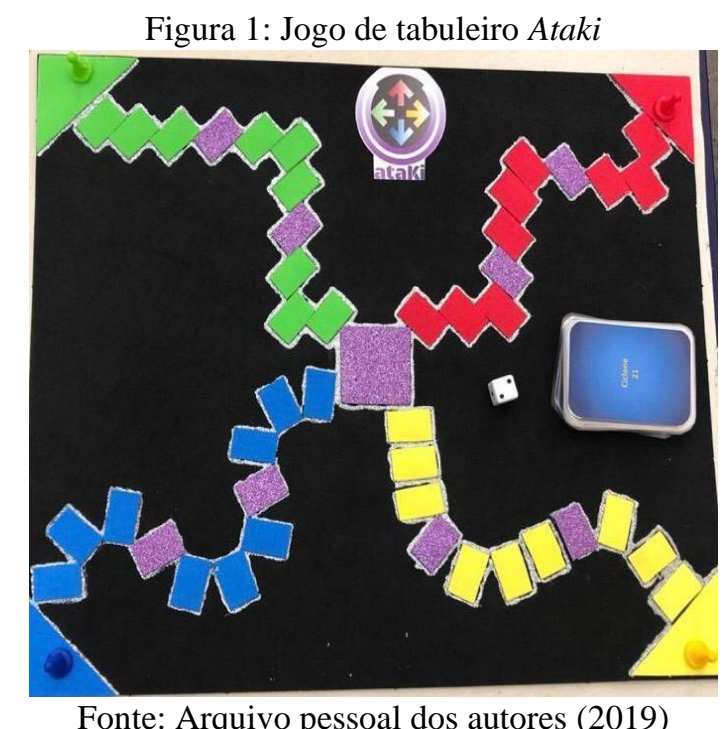

\subsection{Desenvolvimento do jogo}

A proposta desta metodologia foi utilizar um jogo educativo para auxiliar professor e aluno na construção de conceitos relacionados à ciclone e hidrociclone, conceitos estes abordados anteriormente em uma atividade assíncrona.

Incialmente, os estudantes se dividiram em grupos para planejar o desenvolvimento do jogo. Trata-se de um jogo de tabuleiro para fins didáticos, objeto de estudo e entretenimento.

Definido o tipo de jogo a ser utilizado, partiu-se para a etapa de construção: um tabuleiro em formato de pista com várias casas, distintas por cinco cores (amarelo, azul, verde, vermelho e roxo), sendo as casas roxas de sorte ou revés.

O Ataki foi projetado como um jogo de perguntas e respostas, disposto com 11 casas que formam um trajeto a ser trilhado.

O material do jogo é composto por tabuleiro, confeccionado em folha de isopor e EVA, um dado, quatro peões de cores diferentes (amarelo, azul, verde e vermelho) e cartas contendo perguntas e respostas, numeradas em sequência, as quais foram impressas, em papel couchê, em impressora em cores e plastificadas para um maior durabilidade.

As perguntas, contidas nas cartas, também foram elaboradas pelos estudantes, em grupo, e em seguida enviadas a professora responsável pelo $\mathrm{CC}$, de modo que pudessem ser revisadas antes da confecção das cartas. 
"Ataki" foi elaborado em um intervalo de 2 semanas, prazo estipulado pela professora responsável pela dinâmica.

\subsection{Regras do jogo}

O passo seguinte foi repassar as regras e explicar a dinâmica para os demais estudantes da turma e para a professora do componente curricular.

Para jogar são necessários no mínimo dois e no máximo quatro participantes por equipe.

Inicialmente, cada equipe deve jogar o dado para saber a ordem de jogada. A equipe que tirar o maior número será a primeira e assim sucessivamente.

Uma vez determinada a ordem das equipes jogarem, a primeira retira uma carta-pergunta, a qual era respondida pelo componente que iniciou a jogada (sem a ajuda dos demais do grupo), podendo esta ser referente ao assunto de ciclone ou hidrociclone. $\mathrm{O}$ tempo para resposta da pergunta é de um minuto. A cada rodada, um estudante diferente deverá participar.

Ocorrendo o acerto, a equipe movimenta o peão referente ao número de casas descritas na carta-pergunta. Havendo erro na resposta, a equipe deve retornar quantas casas estiverem descritas na carta-pergunta.

Assim como a maioria dos jogos de tabuleiro, o Ataki foi projetado para implementar uma dinâmica, em que existe bonificação, casas neutras e casas de penalidade. As casas em roxo são de sorte ou revés. Se por um acaso a equipe passar por essas casas, o representante deve jogar o dado. Para os números de um, três e cinco se tem o revés, os quais o jogador deve cumprir, sendo um - volte uma casa; três - fique uma rodada sem jogar e cinco - volte três casas. Para os números dois, quatro e seis, se têm as sortes, as quais o jogador será bonificado, sendo: dois - avance uma casa; quatro - escolha um adversário para ficar uma rodada sem jogar; seis escolha um adversário para voltar três casas.

A equipe que acertar o maior número de questões pode ou não chegar ao final do jogo. Caso nenhuma equipe consiga chegar ao final, aquela que avançou mais casas será a vencedora

\subsection{Aplicação do jogo}

O jogo Akati foi aplicado na disciplina de Operações de Separação I, durante o segundo semestre do ano de 2019. Doze estudantes estavam inscritos na disciplina.

A turma foi dividida em equipes, na qual cada uma escolheu um peão de cor diferente (amarelo, azul, verde e vermelho), para representá-la.

Durante a dinâmica do jogo, quando uma das equipes não conseguia responder uma dada pergunta, esta era discutida em conjunto com a turma e a professora, tecendo novas oportunidades de aprendizagem.

Segundo Gehlen, et al., (2012):

[...] o papel do professor durante a problematização inicial é diagnosticar apenas o que os estudantes sabem e pensam sobre uma determinada situação. É ele que organiza a discussão, não para fornecer explicações prontas, mas, sim, para buscar o questionamento das interpretações assumidas pelos estudantes

A Figura 2 mostra momento de interação entre os jogadores. 
Figura 2: Momento de interação entre os jogadores

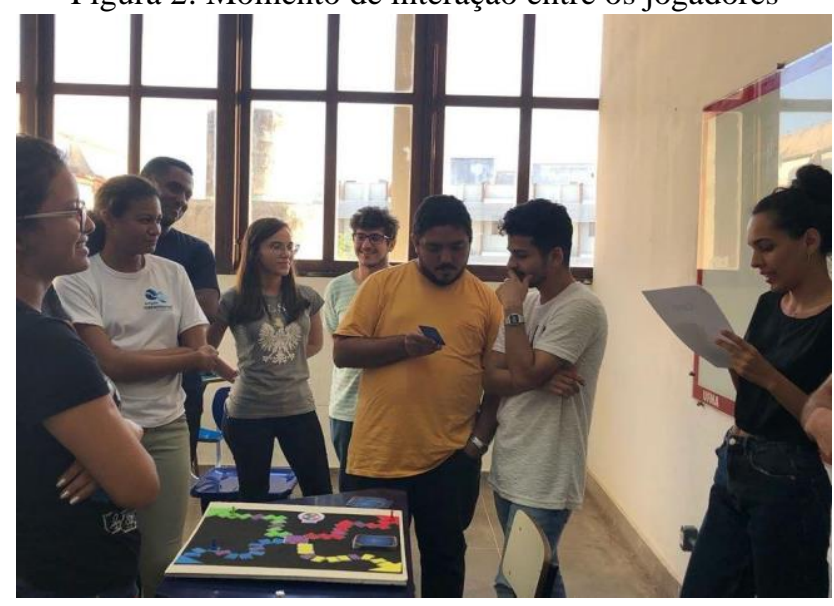

Fonte: Arquivo pessoal dos autores (2019)

\subsection{Avaliação do jogo}

A fim de avaliar a percepção dos estudantes quanto a utilização do jogo Ataki e seu nível de satisfação, como ferramenta de auxílio da aprendizagem, foi disponibilizado questionário eletrônico ${ }^{1}$, por meio da plataforma Google.

Foram elaboradas dez questões objetivas e uma pergunta subjetiva, sendo esta última opcional, utilizada para saber quais as possíveis sugestões, na visão dos estudantes, para aprimoramento do jogo e da metodologia de ensino.

As perguntas objetivas foram construídas a partir da escala de Likert (1932), de cinco pontos, sendo: 1) discordo totalmente, 2) discordo, 3) indiferente (ou neutro), 4) concordo e 5) concordo totalmente.

\section{RESULTADOS E DISCUSSÕES}

Os dados obtidos foram analisados de forma quantitativa através de questionário, onde pôde-se mensurar o grau de satisfação dos estudantes com o uso do jogo como forma de ensinoaprendizagem.

Os resultados presentes nas Figuras 3 e 4 são correspondentes à aplicação no CC de Operações de Separação I, segundo semestre do ano 2019, para os estudantes do curso de química industrial da UFMA.

O questionário foi aplicado somente aos estudantes da turma que não participaram do planejamento e construção do jogo Ataki.

\footnotetext{
${ }^{1}$ https://docs.google.com/forms/d/1NNYsl1Byc5H4RY6NdjdCiQR72CAKRNneUGL6_5F4oEw/edit
} 
"Os desafios para formar hoje o engenheiro do amanhã"

Figura 3: Avaliação da satisfação dos estudantes quanto ao emprego do jogo Ataki no processo de ensino e aprendizagem do CC

O conteúdo do jogo é relevante para seu aprendizado?

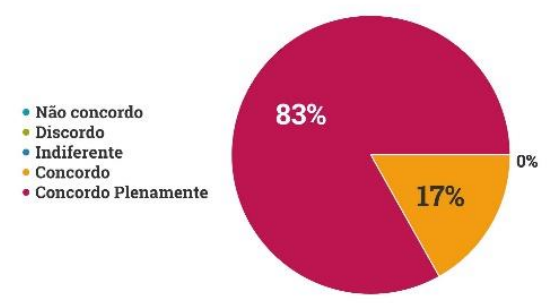

(a)

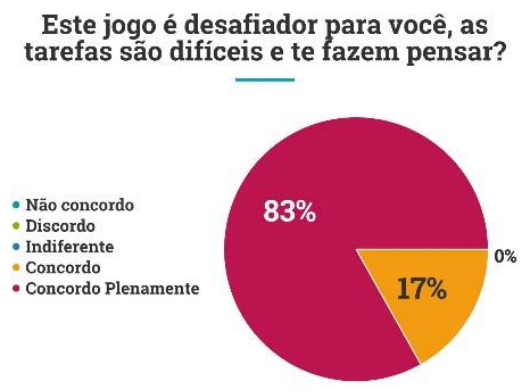

(c)

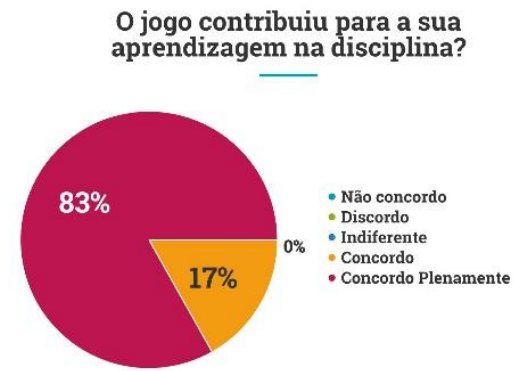

(b)

Fonte: Questionário próprio elaborado pela docente responsável do CC

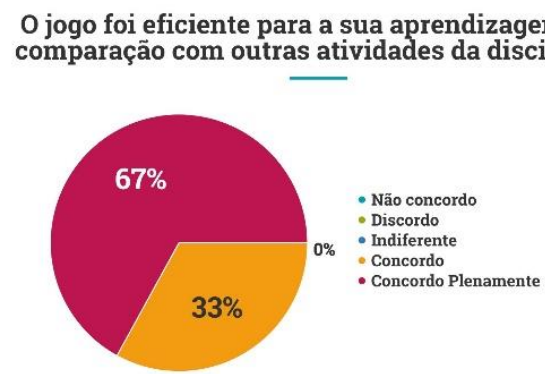

(d)

Os resultados apresentados na Figura 3a, 3b e 3c, respectivamente, revelam, na percepção dos usuários, que o jogo de tabuleiro cumpriu com o caráter educativo, sendo que $83 \%$ dos estudantes concordaram plenamente e $17 \%$ concordam que o conteúdo abordado no jogo foi relevante e contribuiu para seu aprendizado, além do jogo ter sido desafiador.

A Figura 3d mostra que $67 \%$ dos usuários concordam plenamente que o jogo foi eficiente para a sua aprendizagem, em comparação com outras atividades do CC, o que corrobora que a dinâmica cumpriu com seu papel para o processo de ensino e aprendizagem. 
(C) COBENGE 2020

"Os desafios para formar hoje o engenheiro do amanhã"
$\mathrm{Ol} \mathrm{a} \mathrm{O3}$ de dezembro Evento On-line

Figura 4: Resposta dos estudantes quanto ao questionário - questões gerais

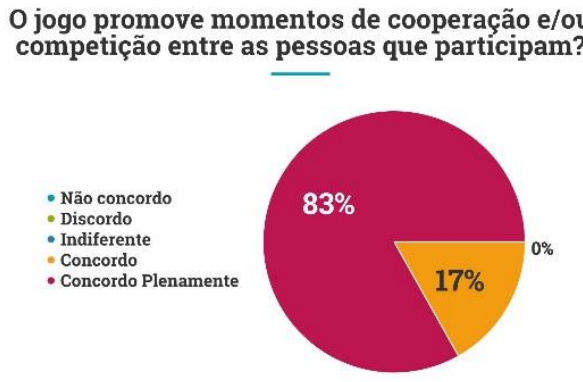

O conteúdo do jogo está conectado com outros conhecimentos que você já possuía?

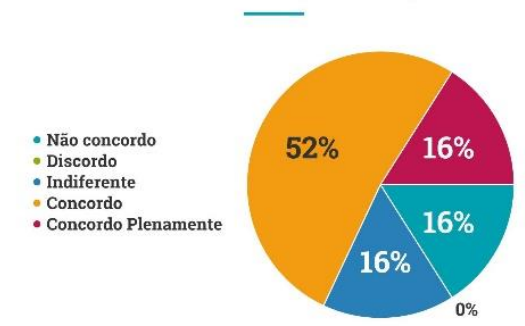

O jogo evolui num ritmo adequado e não fica monótono - oferece novos obstáculos, situações ou variações de atividades?

(a)

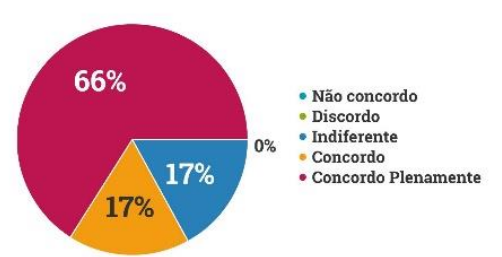

(b)

Conseguiu chegar até o ponto final do jogo (resultado)?

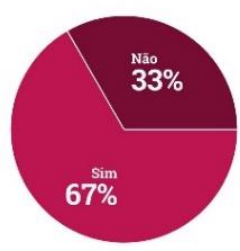

(c)

(d)

Fonte: Questionário próprio elaborado pela docente responsável do CC

As Figuras 4a e 4b, respectivamente, evidenciam que jogo contribuiu para criar uma maior interação entre os estudantes, mantendo-os motivados durante a execução do jogo e estimulando uma competição saudável na qual eles tiveram que utilizar de seus conhecimentos adquiridos ao longo do $\mathrm{CC}$ para responder as perguntas propostas no jogo. Constatou-se também que, $68 \%$ dos usuários afirmaram que os conteúdos abordados no jogo estavam conectados com outros conhecimentos que já possuíam, enquanto $32 \%$ da turma não concordam ou são indiferentes (Figura 4c).

Ao final da dinâmica, 33\% dos usuários não conseguiram finalizar o jogo (Figura 4d), devido a alguma questão respondida sem êxito. Contudo os estudantes foram unânimes em afirmar que o jogo foi fácil de jogar e que eles se divertiram com a metodologia de ensino, confirmando o caráter lúdico da atividade.

Ao questionamento "Sugestões", são reproduzidas literalmente abaixo as duas contribuições:

“Tempo para responder (aluno 01)"

"Avaliar as questões feitas ao longo do jogo (aluno 02)"

Considerando as contribuições, iremos avaliar aumentar o tempo de resposta das questões, bem como, intensificar as discussões das questões durante o jogo, mesmo que a resposta do usuário esteja correta. 
Observou-se, durante a aplicação do jogo, que a metodologia abordada proporcionou um maior interesse e aprendizado do ensino de operações de separação, entusiasmando os estudantes na compreensão dos conteúdos abordados.

Já em relação a metodologia utilizada para construção do jogo, foi perceptível para a docente ,responsável pelo $\mathrm{CC}$, que os estudantes pensaram em todas as situações problemas envolvidas no jogo, que houve problematização, aprendizagem e autoavaliação, pois o processo envolve pesquisa, leitura, estudo e discussões com o grupo, tornando a construção do jogo um processo de profícuo aprendizado e relevância para a formação do estudante.

Foi percebido também que essa atividade conduziu os estudantes a refletir e não apenas a memorizar o assunto abordado, pois foi uma forma integradora das relações da construção do ser entre o social e o científico, que levaram desde a afetividade, os trabalhos em grupo e as relações das regras a serem seguidas, dando maior significado ao processo de ensinoaprendizagem.

Por fim, cabe ressaltar que o jogo apresentado neste trabalho será aplicado, como metodologia de ensino aprendizagem, em 2021, em outras turmas, da qual uma das autoras é a docente responsável pelo CC de Operações de Separação, dos Cursos de Química Industrial e Engenharia Química do Centro de Ciências Exatas e Tecnologia da UFMA.

\section{CONSIDERAÇÕES FINAIS}

Neste trabalho, foram apresentados considerações e resultados da criação de um jogo intitulado Ataki e sua utilização como ferramenta educacional.

O Ataki é um jogo interativo de tabuleiro, desenvolvido para uso em salas de aula, por professores da área de operações de separação na indústria química e que estão dispostos a diversificar o processo de ensino e aprendizagem em suas disciplinas, conforme as orientações das Diretrizes Curriculares Nacionais (DCNs) para os cursos de graduação em Engenharia.

O Ataki é um instrumento lúdico que proporcionou o desenvolvimento e a aplicação de um artefato pedagógico para o ensino de operações de separação, objetivando o envolvimento dos estudantes nos conteúdos trabalhados de forma assíncrona e o equilíbrio entre aprender e divertir, visando ofertar muito mais do que a memorização de conteúdo, mas a formação de cidadãos críticos e conscientes.

A reação dos estudantes diante dessa estratégia, que foge ao tradicional ensino livresco, foi extremamente positiva, demonstrando a importância do uso de diferentes formas de ensinar e aprender.

É importante ressaltar que a estrutura do jogo facilita o seu emprego em outras áreas do conhecimento, requerendo apenas a elaboração das cartas contendo as perguntas e respostas das questões.

A dinâmica utilizada em sala de aula foi, por si só, uma experiência bastante interessante. Para a professora responsável pelo componente curricular, foi enriquecedor o processo criativo com os estudantes, que mostraram muita responsabilidade e dinamismo para trabalhar em grupo. 


\title{
REFERÊNCIAS
}

CARVALHO, C. V. Aprendizagem baseada em jogos: game-based learning. In. II World Congress on Systems Engineering and Information Technology. SPAIN, Anais. Vigo, 2015. ELMÔR FILHO, Gabriel et al. Uma Nova Sala de Aula é Possível - Aprendizagem Ativa na Educação em Engenharia. $1^{\circ}$ edição, Rio de Janeiro: LTC, 2019.

FELCZAK, Jaqueline; WIEST, Luiza S.; SILVA, Elissa D. L. Balanceamento de linha de montagem: um jogo didático para o ensino de engenharia de produção. In: XLV Congresso Brasileiro de Educação em Engenharia, 2017, Santa Catarina. Anais. Joinville, 2017.

GEHLEN, Simoni. T.; MALDANER, Otávio. A.; DELIZOICOV, Demétrio. Momentos Pedagógicos e as etapas da situação de estudo: complementaridades e contribuições para a educação em ciências. Ciência e Educação, Bauru, v. 18, n. 1, p. 1-22, 2012. https://doi.org/10.1590/S1516-73132012000100001

LIKERT, R. A technique for the measurement of attitudes. Archives of Psychology. New York, v. 22, n. 140, p. 5-55, 1932.

OLIVEIRA, Vanderli. F et al. A Engenharia e as Novas DCNs - Oportunidades para Formar Mais e Melhores Engenheiros, $1^{\circ}$ edição, Rio de Janeiro: LTC, 2019.

PIAGET, Jean. O tempo e o desenvolvimento intelectual. In: Os pensadores. São Paulo: Abril Cultural, 1975.

RIBEIRO, Iracira J. C; SILVA, Jerfesson J. S; SILVA, José. E. R; SILVA, Tamires. N; SILVA, Tiago. J. S. CREA em construção: uma proposta de jogo educativo. In: XLVII Congresso Brasileiro de Educação em Engenharia, 2019, Ceará. Anais. Fortaleza, 2019.

\section{ATAKI: BOARD GAME FOR SUPPORTING THE LEARNING TEACHING PROCESS IN THE SEPARATION OPERATIONS DISCIPLINE}

\begin{abstract}
The use of games in education has been increasing over time. The use of this strategy aims mainly increasing learning motivation among students, besides allowing the discussion of the knowledge favoring the learning and its evaluation. This article describes a constructivist activity to support the teaching-learning process in the discipline of separation operations, a mandatory curricular component of the Chemical Engineering, Food Engineering and Industrial Chemistry courses (within the scope of the Federal University of Maranhão UFMA), which consists of in the development of a team board game, with an emphasis on cyclone and hydrocyclone contents. This work describes the details of the dynamics, as well as the application report and a post-game evaluation.
\end{abstract}

Keywords: Board game. Separation Operations. Cyclone. Hydrocyclone. 